\title{
И.С. Пилко, О.В. Дворовенко
}

\section{Библиотечная профессия в зеркале профессиональных стандартов}

Реферат. Освещена кадровая ситуация в российских библиотеках. Поставлена проблема согласования требований к библиотечным специалистам со стороны работодателей, библиотекарей-практиков, организаций профессионального образования, органов управления библиотечной отраслью. Предложен вариант решения проблемы - разработка профессиональных стандартов. Изложен опыт проектирования профессиональных стандартов «Специалист в области библиотечно-информационной деятельности» и «Педагог-библиотекарь». Охарактеризованы объективные предпосылки, основные концептуальные положения стандартизации библиотечно-информационной деятельности, опыт разработки проектов документов на инициативной основе и на основе государственного контракта на выполнение работ. Проведен сравнительный анализ двух проектов в части выделения и описания трудовых функций и действий, предъявления требований к умениям и знаниям специалистов, образовательному статусу работников библиотек. Сделан вывод об уникальности библиотечной профессии, которая отличается профессиональной содержательностью и интеллектуальностью, требует специального образования. Определены перспективы развития дополнительного профессионального образования в библиотечной сфере в соответствии с требованиями профессиональных стандартов: взаимодействие образовательных организаций, осуществляющих подготовку библиотечных специалистов, и библиотек при реализации программ повышения квалификации и профессиональной переподготовки библиотечных кадров на основе применения информационно-коммуникационных и дистанционных образовательных технологий.

Ключевые слова: профессиональные стандарты, специалист в области библиотечно-информационной деятельности, педагог-библиотекарь, трудовые функции, умения, знания, образовательный статус.

Для цитирования: Пилко И.С., Дворовенко О.В. Библиотечная профессия в зеркале профессиональных стандартов // Библиотековедение. 2017. Т. 66, № 1. C. $95-101$.

\section{Объективные предпосылки разработки нового регламента профессии}

Первые десятилетия XXI в. отмечены для библиотечной отрасли России многочисленными «вызовами». Период острого кадрового дефицита сменялся тотальным отсутствием в библиотеках вакансий, порождавшим, в свою очередь, сложности трудоустройства выпускников библиотечных факультетов и отделений, сокращение бюд-

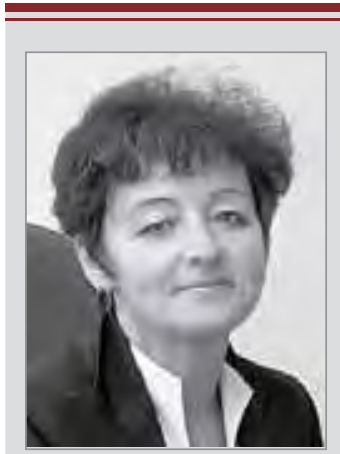

Ирина Семеновна

Пилко,

Санкт-Петербургский государственный институт культуры,

кафедра информационного менеджмента, профессор

Дворцовая наб., д. 2-4, Санкт-Петербург, 191186 , Россия

доктор педагогических наук, профессор E-mail:skip_95@mail.ru

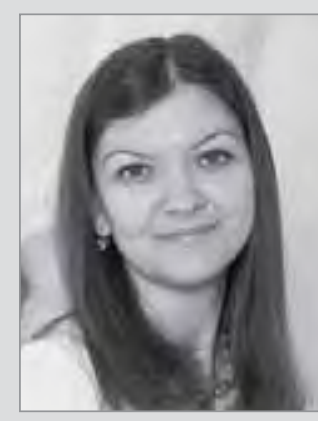

Ольга Владимировна Дворовенко, Кемеровский государственный институт культуры, кафедра технологии документальных коммуникаций, доцент Ворошилова ул., д. 17, Кемерово, 650029, Россия кандидат педагогических наук, доцент E-mail:olga.uso@gmail.com 
жетных мест для желающих получить библиотечную профессию. Складывалась устойчивая тенденция депрофессионализации - уменьшения числа работающих в библиотеках специалистов с базовым библиотечным образованием.

Дискуссию о том, насколько «прогрессивна» эта тенденция и как она влияет на модернизацию библиотечной сферы, мы отложим на будущее. Отметим отсутствие объективной, доступной профессиональной общественности статистики по интересующему нас вопросу. Министерство культуры Российской Федерации, публикуя на своем сайте данные по персоналу подведомственных ему библиотек (http://mkrf.ru/deyatelnost/statistics/ statdata/), ограничивается сведениями о сотрудниках с высшим и средним профессиональным образованием без уточнения показателей профильного (библиотечного) образования. В таком варианте ситуация не вызывает беспокойства: в центральных библиотеках субъектов РФ по итогам 2015 г. $86,3 \%$ сотрудников имеют высшее, $11 \%$ - среднее профессиональное образование; для муниципальных библиотек эти показатели составляют 47,2\% и $46,5 \%$ соответственно.

Корпоративная полнотекстовая база данных (БД) «Центральные библиотеки субъектов Российской Федерации» Российской национальной библиотеки (http://clrf.nlr.ru/) позволяет уточнить эти данные для конкретных библиотек и регионов. Так, сформировав случайную выборку (по две центральные библиотеки из каждого федерального округа), мы получили данные об образовательном статусе работников, отнесенных государственной статистикой (форма № 6-НК) к основному персоналу. По размещенным в БД отчетам за 2015 г. установлено, что $87,5 \%$ сотрудников библиотек имеют высшее, $10,8 \%$ - среднее профессиональное образование (отсутствие существенных расхождений с данными государственной статистики свидетельствует о представительности выборки). При этом только половина (45,9\% лиц с высшим и $55 \%$ - со средним профессиональным образованием) - выпускники образовательных программ по библиотечным (библиотечно-информационным) направлениям подготовки и специальностям.

На рубеже 2010-2011 гг. вузовское сообщество осознало несовершенство новых государственных образовательных стандартов библиотечно-информационного образования. Специалисты не узнавали свою профессию в зеркале общекультурных, общепрофессиональных и профессиональных компетенций. Преподаватели с трудом подстраивались под заданную номенклатуру «знаний, умений, владений», вынужденно дополняли образовательную программу собственными компетенциями, кратно усложняя себе задачу выбора методов и показателей их оценки. Работодатели не понимали и категорически не принимали новую образовательную практику, искали и не находили убедительных ответов на вопросы:
«Что такое бакалавриат? Является ли он высшим образованием? Что умеет бакалавр? На какую должность можно принять магистра?»

Стали очевидными, не требующими дополнительной аргументации:

- несовершенство действующих квалификационных характеристик должностей работников, занятых в различных сферах деятельности, включая библиотечную;

- отсутствие консолидированных требований к профессиональной деятельности со стороны практикующих специалистов и образовательного сообщества;

- недостаточная обоснованность компетентностных моделей специалистов, зафиксированных в федеральных государственных образовательных стандартах высшего и среднего профессионального образования;

- ограничение сферы внедрения компетентностного подхода исключительно сферой профессионального образования [1].

Таким образом, сложились объективные предпосылки для активных действий по согласованию требований основных сегментов профессионального сообщества (работодателей, практикующих специалистов, организаций профессионального образования, органов управления библиотечной отраслью) к библиотечному специалисту.

\section{Концептуальное и методическое обоснование профессиональното стандарта библиотечно- информационной деятельности (2010-2012)}

Изучение отечественного и зарубежного опыта, сложившегося в различных сферах экономической деятельности, показало, что возможным вариантом компетентностно-ориентированной модели специалиста может служить профессиональный стандарт. Инициированная Российским союзом предпринимателей и промышленников (РСПП) практика разработки и внедрения профессиональных стандартов в сфере информационных технологий вдохновила авторов статьи на детальное изучение этого вопроса, готовность адаптировать структуру нового регламента к специфике библиотечно-информационной деятельности, обосновать концепцию и методику его проектирования.

Были определены основные этапы формирования профессионального стандарта. Подробная их дифференциация позволила выстроить алгоритм разработки документа, предложить вариант распределения ответственности, определить реальные сроки реализации проекта, выявить и оценить требуемые ресурсы [2].

Федеральный закон «Об образовании в Российской Федерации» (2012) зафиксировал требование учитывать положения соответствующих профессиональных стандартов при формирова- 
нии федеральных государственных образовательных стандартов профессионального образования (ст. 11, п. 7). Это внушало оптимизм и позволило приступить к продвижению в профессиональном сообществе идеи разработки профстандарта библиотечно-информационной деятельности. Возможность ее реализации в качестве инициативного проекта Российской библиотечной ассоциации (РБА) на тот момент не вызывала сомнений.

В 2012 г. было проведено масштабное анкетирование руководителей и ведущих специалистов 276 библиотек - членов РБА с целью выявления их отношения к выдвинутому предложению. Ответы были получены от 104 респондентов из 28 субъектов РФ: 84\% опрошенных не только поддержали идею разработки профессионального стандарта, но и выразили готовность участвовать в его создании [3]. Несмотря на позитивный отклик и поддержку инициативы в различных аудиториях и территориях, довести ее до уровня практической реализации не удавалось. Основной аргумент оппонентов сводился к нецелесообразности стандартизировать библиотечную профессию в силу ее креативного, не поддающегося формализации начала.

\section{Разработка проекта профессионального стандарта специалиста в области библиотечно-информационной деятельности (2013)}

В 2012 г. Указом Президента РФ «О мероприятиях по реализации государственной социальной политики" профессиональному стандарту был придан статус официального документа. В ноябpe 2012 г. Министерством труда и социальной защиты РФ был утвержден план-график подготовки в 2013-2014 гг. 852 профессиональных стандартов, в том числе 25 - для сферы искусства, культуры, физической культуры и спорта.

Проект профессионального стандарта «Специалист в области библиотечно-информационной деятельности» вошел в объявленный министерством перечень документов, разработка которых за счет средств федерального бюджета планировалась в 2013 году. Московским государственным университетом культуры и искусств (МГУКИ) был заключен государственный контракт на подготовку этого проекта. К участию в его разработке были привлечены представители Академии переподготовки работников искусства, культуры и туризма (АПРИКТ) и Кемеровского государственного университета культуры и искусств (КемГУКИ).

Кемеровской группе разработчиков было поручено, в частности, описание трудовых функций, обеспечивающих работу библиотечного персонала с электронными документами и данными. Владение информационно-коммуникационными технологиями - неотъемлемый компонент профессиональной компетентности современного библиотечного специалиста, неза- висимо от его функционала. Предстояло решить сложную задачу - предложить процессную модель работы с электронными документами и данными в библиотеке, актуальную для сотрудников любых подразделений и производственных участков.

Работу кемеровской группы условно можно разделить на три этапа: 1) определение концептуальной основы проектирования (процессный подход) и обоснование структуры регламента (номенклатуры обобщенных трудовых функций); 2) содержательная проработка функций библиотечных специалистов по работе с электронными документами и данными; 3) согласование подготовленных материалов с разработками творческого коллектива МГУКИ.

Конечным результатом объединенных усилий стал проект профессионального стандарта. Структуру документа определили семь обобщенных функций, описывающих библиотечно-информационную деятельность (см. табл.). К обобщенным и отдельным трудовым функциям были добавлены трудовые действия, реализуемые в автоматизированном режиме, либо связанные с электронными документами и данными. Детально методика работы над формированием проекта профессионального стандарта описана в монографии [4, с. 165-204].

В процессе редактирования из раздела профессионального стандарта «Другие характеристики» были исключены компетенции, требуемые для реализации конкретных трудовых функций. Это случилось еще до момента публичного (в целом весьма благожелательного) обсуждения проекта и не способствовало необходимому взаимопониманию всех сегментов профессионального сообщества в отношении предъявляемых требований к специалисту библиотечно-информационной сферы с позиций компетентностного подхода.

\section{Разработка проекта профессионального стандарта педагога-библиотекаря (2014-2015)}

В 2014 г. руководство Русской школьной библиотечной ассоциации (РШБА) инициировало подготовку проекта профессионального стандарта «Педагог-библиотекарь» и привлекло к этой работе коллектив преподавателей КемГУКИ и научных сотрудников НИИ информационных технологий социальной сферы. Новый проект был призван интегрировать образовательную составляющую, воспитательную направленность деятельности педагога-библиотекаря общеобразовательной организации и его традиционно «библиотечные» трудовые функции.

Нормативной базой проектирования профессионального стандарта педагога-библиотекаря послужили законы РФ «Об образовании», «О библиотечном деле», национальная доктрина 
Структура описания профессиональных функций в проектах профессиональных стандартов «Специалист в области библиотечно-информационной деятельности» и «едагог-библиотекарь»

Специалист в области библиотечноинформационной деятельности

Обобщенные трудовые функиии

Формирование библиотечного фонда Осуществление работ по сохранению библиотечного фонда

Организация справочно-поискового аппарата библиотеки

Справочно-библиографическое и

информационное обслуживание пользователей Библиотечное обслуживание пользователей Предоставление культурно-просветительных и досуговых услуг пользователям библиотеки

Научно-аналитическая, методическая и консультационная работа в области библиотечно-информационной деятельности
Педагог-библиотекарь

Библиотечно-информационное сопровождение основных образовательных програлм общего образования

Выполнение работ по комплектованию, учету, обработке, организации и сохранению фонда

Организация справочно-библиографического аппарата библиотеки общеобразовательной организации

Создание информационных продуктов

и ресурсов библиотеки общеобразовательной организации

Организация обслуживания пользователей библиотеки общеобразовательной организации

Предоставление культурно-просветительных и досуговых услуг воспитанникам, учащимся, педагогическим работникам, родителям (законным представителям) и другим участникам образовательных отношений

Организация деятельности библиотеки общеобразовательной организации образования, федеральные государственные образовательные стандарты общего образования, а также профессиональный стандарт «Педагог (педагогическая деятельность в сфере дошкольного, начального общего, основного общего, среднего общего образования)» и проект профессионального стандарта «Специалист в области библиотечноинформационной деятельности» .

На основе изучения квалификационных характеристик, должностных инструкций, педагогического опыта, анализа и декомпозиции трудовой деятельности педагогических работников различных уровней общего образования и практической деятельности школьных библиотекарей была составлена функциональная карта профессиональной деятельности педагога-библиотекаря, включающая три основные функции:

1) образовательная, воспитательная и просветительская деятельность, направленная на реализацию функций обучения, воспитания и развития подрастающего поколения;

2) проектирование и реализация образовательных программ по формированию основ информационной культуры и обеспечению информационной безопасности личности участников образовательных отношений;

3) библиотечно-информационное сопровождение всех направлений деятельности общеобразовательной организации (см. табл.).

Наибольшие сложности в ходе разработки проекта этого документа возникли при моделировании педагогической составляющей деятельности педагога-библиотекаря. Эти вопросы не получили достаточного научно-методического обоснования в профессиональной среде и вызвали наибольшие разногласия у работников школьных библиотек и руководителей общеобразовательных организаций при последующем публичном обсуждении проекта. Разработчики пошли путем гармонизации функций педагога-библиотекаря с соответствующими положениями вступившего в действие профессионального стандарта педагога.

Уникальность проекта профессионального стандарта «Педагог-библиотекарь» нашла выражение в описании обобщенной трудовой функции «Педагогическая деятельность по формированию основ информационной культуры и обеспечению информационной безопасности личности участников образовательных отношений». Был дан четкий ответ на вопрос о специфике педагогической деятельности педагога-библиотекаря, связанной с проектированием и реализацией программ указанной тематики, а также программ повышения информационно-технологической компетентности педагогических работников общеобразовательной организации.

Декомпозиция обобщенной трудовой функции педагога-библиотекаря «Библиотечно-информационное сопровождение основных образовательных программ общего образования п поводилась с опорой на базовые положения проекта профессионального стандарта «Специалист в области библиотечно-информационной деятельности». Однако специфика школьной библиотеки нашла выражение и в структуре трудовых функций, и в их содержательном наполнении (см. табл.).

Проект профессионального стандарта был опубликован в Интернете и имел широкое общественное обсуждение на различных библиотечных форумах. РШБА организовала доступное каждому жела- 
ющему онлайн-голосование по проекту документа. В ходе серии вебинаров, организованных КемГУКИ и РШБА, школьные библиотекари активно высказывали свое мнение относительно содержательного наполнения документа. Большинство конструктивных замечаний были учтены при доработке проекта.

\section{Первые результаты стандартизации деятельности специалиста библиотечно- информационной сферы}

Российское законодательство определяет область применения образовательных стандартов, предписывая учитывать их требования: работодателям - при формировании кадровой политики и управлении персоналом, организации обучения и аттестации работников, разработке должностных инструкций, установлении систем оплаты труда; разработчикам федеральных государственных образовательных стандартов профессионального образования - в процессе их доработки и актуализации; образовательным организациям профессионального образования - при разработке и реализации многоуровневых образовательных программ. Обязательность применения основных положений и сроки введения в действие профессиональных стандартов корректируются Министерством труда и социальной защиты РФ по мере их утверждения. Вызывает беспокойство тот факт, что судьба проекта профессионального стандарта «Специалист в области библиотечно-информационной деятельности», прошедшего все установленные правилами стадии и процедуры подготовки и представленного на утверждение три года назад, остается неизвестной. Он не числится в Реестре профессиональных стандартов (http://profstandart.rosmintrud.ru), перечнях подготовленных или проходящих обсуждение проектов. Лишь компания «КонсультантПлюс» разместила этот проект на своем сайте (http://base.consultant.ru).

За годы существования в качестве проекта документ многократно обсуждался на региональных и всероссийских библиотечных форумах, в профессиональной печати [5], социальных сетях, при личном общении. Острые дискуссии разворачиваются вокруг положений, предъявляющих требования к образованию, повышению квалификации, стажу работы; реже обсуждаются ассортимент и содержательное наполнение трудовых функций и соответствующих им умений и знаний. Справедливыми представляются замечания, связанные с некорректностью формулировок отдельных трудовых функций. Так, можно согласиться с предложением переименовать обобщенную трудовую функцию «библиотечное обслуживание» в «документное обслуживание», заменить «справочно-библиографическое и информационное обслуживание» на «справочно-библиографическое и библиографическое информирование» с возможным последующим их делением на две самостоятельные функции.
Стоит принять во внимание то обстоятельство, что обсуждаемый проект по определению не мог быть идеальным, поскольку подобный документ разрабатывался впервые, сроки государственного контракта всегда ограничены, работа велась методом поиска компромиссных решений, поскольку в профессиональном сообществе отсутствует единство мнений по многим вопросам, включая терминологические.

За годы, прошедшие с момента сдачи проекта на утверждение, произошли серьезные изменения в библиотечной отрасли, библиотечно-библиографическое знание пополнилось учебниками бакалаврской серии для направления подготовки «Библиотечно-информационная деятельность», введены в действие новые терминологические стандарты по информации, библиотечному и издательскому делу, начата разработка ГОСТ «Библиотечное обслуживание: термины и определения». Все это обусловливает необходимость доработки документа, тем более что практика изменения и дополнения утвержденных и введенных в действие профессиональных стандартов (например, педагогического) становится обычным явлением.

В этом отношении более благополучным выглядит проект профстандарта «Педагог-библиотекарь», который был широко представлен в Интернете, что позволило кумулировать поступающие замечания и оперативно на них реагировать. В рамках реализации «Концепции развития школьных информационно-библиотечных центров» предусмотрены мероприятия по доработке профессионального стандарта «Педагог-библиотекарь» в 2017 году. Организацией этой работы активно занялись РШБА и Информационный центр «Библиотека им. К.Д. Ушинского» Российской академии образования, и это внушает сдержанный оптимизм.

Каковы же промежуточные результаты пути, пройденного в направлении разработки стандартов библиотечной профессии? На наш взгляд, они сводятся к следующему:

1. Удалось доказать уникальность библиотечной профессии. Абсолютное большинство трудовых функций «основного персонала» работников библиотеки (см. табл.) специфичны именно для библиотечного производства и требуют специальной подготовки. Исключение составляет трудовая функция «Предоставление культурно-просветительных и досуговых услуг пользователям библиотеки», которая реализуется не только в библиотеках, но и в других социокультурных и образовательных учреждениях. Сравнив содержательное наполнение проектов профессиональных стандартов специалиста в области библиотечноинформационной деятельности, педагога-библиотекаря и утвержденных профстандартов в сфере образования (педагогов общего, профессионального, дополнительного - общего и профессионального образования), мы найдем множество существенных 
отличий. Таким образом, труд работников библиотек обладает всеми атрибутами профессиональной деятельности специалиста: отличается профессиональной содержательностью и интеллектуальностью, требует специального образования. Это позволяет бороться с профессиональным радикализмом в двух его проявлениях: «В библиотеке могут работать специалисты с любым профессиональным образованием!» и «Библиотекари могут все!» .

2. Несомненным достоинством разработанных проектов является то, что необходимые для каждого трудового действия умения и знания определены, исходя из анализа самой трудовой деятельности, а не заимствованы из «Единого квалификационного справочника должностей руководителей, специалистов и служащих", из образовательных стандартов высшего или среднего профессионального образования. Смеем полагать, что именно эти умения и знания актуальны для практикующего специалиста, занятого конкретным видом работ в библиотеке.

3. В проекте профстандарта «Специалист в области библиотечно-информационной деятельности» предпринята, возможно, не во всем удавшаяся попытка дифференцировать трудовые функции по степени сложности. Это актуально для крупных библиотек, централизованных библиотечных систем с возможностями вертикальной карьеры. В проекте профстандарта «Педагог-библиотекарь» это было сделать сложно по причине отсутствия у абсолютного большинства школьных библиотек возможности иметь более $0,5-1$ ставки работника. Однако в ходе нового этапа доработки проекта такая возможность активно обсуждается.

4. В анализируемых проектах предъявляются достаточно жесткие требования к профессиональной подготовке: среднее библиотечное, высшее библиотечно-информационное или дополнительное библиотечно-информационное образование. Для педагога-библиотекаря базовым признается педагогическое или библиотечно-информационное (библиотечное) образование с последующей профессиональной переподготовкой по отсутствующему профилю деятельности. Повышение квалификации предусмотрено для педагога-библиотекаря раз в три года, для специалиста в области библиотечно-информационной деятельности - раз в пять лет. Безусловно, учитывая сложившуюся в библиотечной отрасли кадровую ситуацию, это очередной «вызов» ее развитию. Однако не следует драматизировать ситуацию, стоит обратить внимание на сферу общего, профессионального и дополнительного образования, в которой после принятия профессиональных стандартов педагога значительно вырос спрос на повышение квалификации и профессиональную переподготовку педагогических кадров. Библиотеки давно и успешно занимаются «внутренним» (корпоративным) повышением профессиональной квалификации. Так, 46 из 150 мероприятий «Сводного плана основных профессиональных меропри- ятий РБА на 2017 год» связаны с дополнительным профессиональным образованием. По нашим многолетним наблюдениям, примерно одна треть докладов, представляемых на ежегодной конференции РБА, посвящены этой теме. Если объединить усилия профильных факультетов вузов культуры, библиотечных отделений колледжей культуры и библиотек для разработки и реализации совместных (сетевых) образовательных программ повышения квалификации и профессиональной переподготовки специалистов библиотечно-информационной сферы и использовать для их трансляции информационно-коммуникационные и дистанционные образовательные технологии, деятельность будет иметь значительный синергетический эффект. Подобный позитивный опыт имеет Институт информационных и библиотечных технологий КемГИК, к этой работе подключается библиотечно-информационный факультет Санкт-Петербургского государственного института культуры.

Таким образом, потенциал разработанных проектов профессиональных стандартов обширен и не ограничивается предписанной нормативными документами «областью применения». Это реальная основа гармонизации различных регламентов библиотечно-информационной деятельности, выстраивания преемственности между уровнями профессионального образования и налаживания конструктивных связей с практической деятельностью, принятия взвешенных управленческих решений. Косвенно новые регламенты задают возможные перспективы развития библиотечной профессии, указывают лакуны в реализации библиотечной политики. Хотелось бы пожелать более внимательного и «включенного» отношения к профессиональному стандарту всех субъектов библиотечного сообщества.

\section{Список источников}

1. Пилко И.С. О кадрах, решающих все. На пути к созданию профессионального стандарта / Библиосфера. 2011. № 7. С. 15-16.

2. Усольцева О.В. Профессиональный стандарт как модель деятельности специалиста библиотечно-информационной сферы // Библиосфера. 2010. № 2. C. $43-48$.

3. Абалакова O.В. Разработка профессионального стандарта библиотечной деятельности: мнение работодателей // Вестник Казанского государственного университета культуры и искусств. 2012. Вып. 4. C. $126-128$.

4. Пилко И.С., ТараненкоЛ.Г., Ли М.Г., Абалакова О.В. Библиотечно-информационное образование: новые концепции и технологии развития : моногр. / науч. ред. И.С. Пилко. Москва : Литера, 2014. 330 с.

5. Олефир С.В. Профессиональные стандарты и профессиональное развитие библиотечного специалиста // Научные и технические библиотеки. 2016. № 11. C. $52-59$. 


\title{
Library Profession's Reflection in the Professional Standards
}

Irina S. Pilko,

St. Petersburg State Institute of Culture, 2-4 Dvortsovaya Nab., St. Petersburg, 191186, Russia

E-mail:skip_95@mail.ru

Olga V. Dvorovenko,

Kemerovo State Institute of Culture, 17 Voroshilov Str., Kemerovo, 650056, Russia

E-mail: olga.uso@gmail.com

\begin{abstract}
The article describes staffing situation in the Russian libraries. It is posed the problem of harmonization of the requirements for library professionals between employers, practicing librarians, educational organizations and the government bodies in the library sector. The proposed solution of the problem is the development of professional standards. The paper exposes the experience in the design of professional standards for "Library and Information Work Specialist" and "Teacher-Librarian". There are characterized the objective prerequisites, the basic conceptual provisions of the standardization of library and information activity, experience in the development of draft documents on a proactive basis and on the basis of the state contract for execution of works. Comparative analysis of two projects in the terms of selection and description of job functions and work activities, requirements to skills and knowledge of specialists, to the educational status of librarians is conducted. There is made the conclusion that librarian is a unique and intellectual profession which requires the specialized education. There are defined the prospects of development of additional professional education in the library sphere in accordance with the requirements of professional standards: interaction of educational institutions engaged in training of librarians with libraries in the implementation of programs of improvement of professional skill growth and professional retraining of library staff on the basis of application of information, communication and distance learning technologies.
\end{abstract}

Key words: Professional Standards, Library and Information Work Specialist, Teacher-Librarian, Job Functions, Skills and Knowledge, Educational Status.

Citation: Pilko I.S., Dvorovenko O.V. Library Profession's Reflection in the Professional Standards, Bibliotekovedenie [Library and Information Science], 2017, vol. 66, no. 1, pp. 95-101.

\section{References}

1. Pilko I.S. O kadrakh, reshayushchikh vse. Na puti k sozdaniyu professional'nogo standarta [About the Cadres that Are All-Important. On the Way to Creating the Professional Standard], Bibliosfera [Bibliosphere], 2011, no. 7, pp. 15-16.

2. Usoltseva O.V. Professional'nyi standart kak model' deyatel'nosti spetsialista bibliotechnoinformatsionnoi sfery [Professional Standard as a Model of the Library and Information Activity of a Specialist], Bibliosfera [Bibliosphere], 2010, no. 2, pp. $43-48$.

3. Abalakova O.V. Razrabotka professional'nogo standarta bibliotechnoi deyatel'nosti: mnenie rabotodatelei [Development of the Professional Standard of Library Activity: the Employers'
Opinion], Vestnik Kazanskogo gosudarstvennogo universiteta kul'tury i iskusstv [Bulletin of the Kazan State University of Culture and Arts], 2012, issue 4, pp. $126-128$.

4. Pilko I.S., Taranenko L.G., Li M.G., Abalakova O.V. Bibliotechno-informatsionnoe obrazovanie: novye kontseptsii i tekhnologii razvitiya [Library and Information Education: the New Concepts and Technologies of Development]. Moscow, Litera Publ., 2014, $330 \mathrm{p}$.

5. Olefir S.V. Professional'nye standarty i professional'noe razvitie bibliotechnogo spetsialista [Professional Standards and Professional Growth of Library Specialists], Nauch. i tekhn. $b$ - $k i$ [Scientific and Technical Libraries], 2016, no. 11, pp. 52-59. 